Article

\title{
Design of A Streamwise-Lateral Ski-Jump Flow Discharge Spillway
}

\author{
Jun Deng, Wangru Wei ${ }^{*}$, Zhong Tian $\mathbb{D}$ and Faxing Zhang
}

State Key Laboratory of Hydraulics and Mountain River Engineering, Sichuan University, Chengdu 610065, China; djhao2002@scu.edu.cn (J.D.); tianzhong@scu.edu.cn (Z.T.); zhfx@scu.edu.cn (F.Z.)

* Correspondence: weiwangru@scu.edu.cn

Received: 11 September 2018; Accepted: 1 November 2018; Published: 6 November 2018

\begin{abstract}
Spillway outlet design is a major issue in hydraulic engineering with high head and large discharge conditions. A new type of design for a streamwise-lateral spillway is proposed for ski-jump flow discharge and energy dissipation in hydraulic engineering. The water in the spillway outlet is constrained by three solid walls with an inclined floor, a horizontal floor on the bottom and a deflected side wall in the lateral direction. The water flow releases in a lateral direction into the plunge pool along the streamwise direction. It generates a free jet in the shape of " $\cap$ " in a limited area, causing the water to fully diffuse and stretch in the air simultaneously, and drop into the plunge pool to avoid excessive impact in the plunge pool. The formation mechanism for the flow pattern is analyzed, and the results show that the optimum inclination is an angle range of $30^{\circ} \sim 45^{\circ}$ for a good performance of free ski-jump jet diffusion shape.
\end{abstract}

Keywords: ski-jump flow; spillway outlet; jet trajectory; energy dissipation; experimental model

\section{Introduction}

Energy dissipation is always a major issue in hydraulic engineering [1,2], especially for large discharge and complex geological conditions. Ski-jump energy dissipation has prevailed among the hydraulic engineering, considering the construction cost and dissipation performance [3-5]. The characteristics of this ski-jump are the free jets diffusing and aerating in the air $[6,7]$ and then dropping into the water downstream, causing energy dissipation through shearing and disturbance. In the traditional design, water flow discharges in the spillway or steep chute and a flip bucket is set at the end of the spillway to make the water release into the flow [8,9]. The various geometries of flip buckets include a wide range of deflection angles, radius, takeoff angles, etc. [10-14].

In order to improve the energy dissipation rate and reduce the impact on the bottom of the plunge pool, the free jet is always made to widely diffuse in the air in both streamwise and lateral directions, and is dropped far away from the dam for safety $[15,16]$. Given the enormous flow discharge and velocity, the common ski-jump is not efficient, considering the energy dissipation performance and other damaging problems. In order to make the ski-jump flow diffuse in a certain direction, researchers and engineers developed a series of structure design to drive the water jet. The specific structures [17-19], such as a contract side wall or a bucket radius of flip bucket, can adjust the water jet to a certain direction. However, when the flow velocity exceeds $30-50 \mathrm{~m} / \mathrm{s}$, the hydrodynamic pressures on the structure is another important issue, which is extremely dangerous to outlet structure safety. The recent study on the flip bucket proposed a new design principle that is take full advantage of the natural pressure difference at the lateral direction to make more contribution, based on the motion characteristic of high-speed flow. The well performance of long-narrow ski-jump flow on the Jinping-I flood discharge tunnel showed much lower pressure on the structure of a leak-floor flip bucket than that of a lateral contraction of side-wall design. However, there have been limited applications of 
flip buckets for two reasons: (1) dissipation area and (2) free jet diffusion shape. For some projects, the dissipation area is limited, such as in valleys and in unsatisfactory souring conditions of river courses. The free jet diffusion shape influences the aeration and impact performance directly, and the effect is pivotal in the limited dissipation area.

In the present study, a new spillway design for a ski-jump streamwise-lateral discharge spillway is proposed for the two stated reasons. The spillway side wall close to the plunge pool is removed and an inclined floor is set along the streamwise direction. This makes the water flow release laterally as it moves downstream, and the free jet shape makes the most of the space as it diffuses in the air. The formation mechanism and characteristics of the water jet are presented, based on experiments and numerical simulation.

\section{Physical Structure of the Streamwise-Lateral Discharge Spillway}

The design of the streamwise-lateral discharge spillway is shown in Figure 1. The spillway is set on the right side of the plunge pool and the axis of the spillway is parallel to the plunge pool in the streamwise direction. The side wall of the spillway closed to the plunge pool (left wall in the present study) is removed (in contrast to the traditional spillway) and an inclined floor is set between the horizontal bottom floor and the right-side wall. An anti-arch design is connected to the straight part of the side wall, which is designed to deflect water into the plunge pool. The intersection part between the horizontal floor and the inclined floor is the diagonal line of the spillway. Here, $X$ is the streamwise coordinate which is perpendicular to the cross-section $Y-Z$, where $Y$ is the lateral coordinate and $Z$ is the vertical coordinate, respectively.

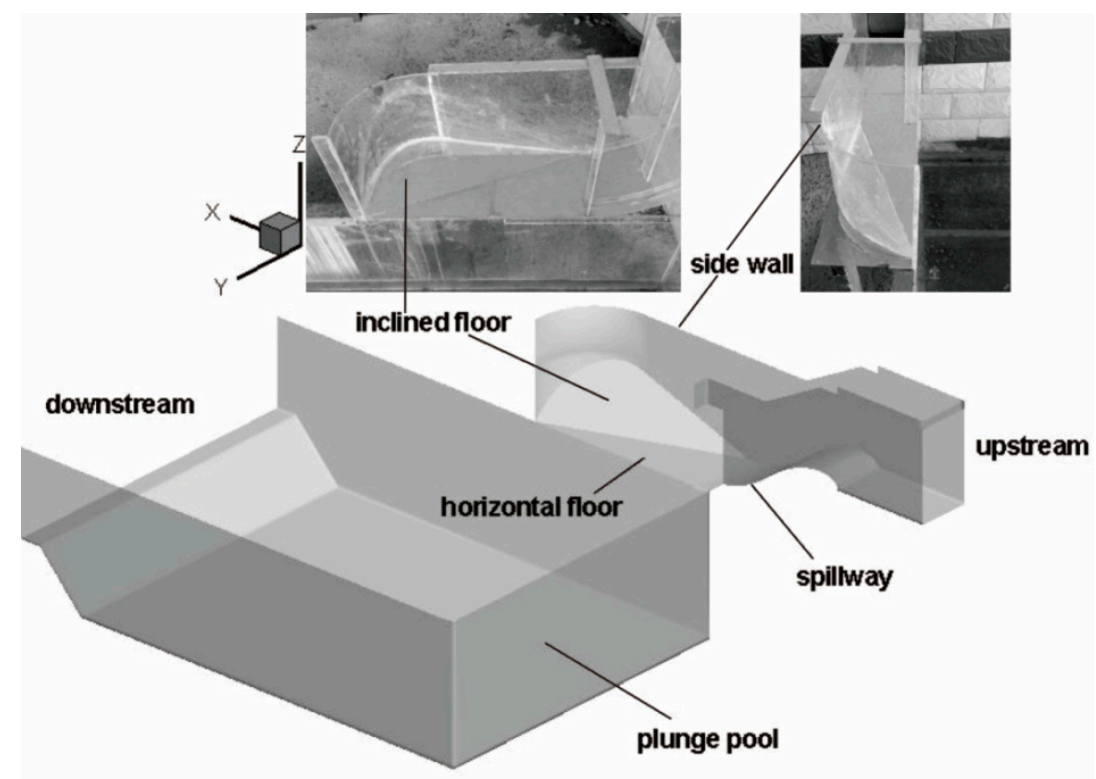

(a)

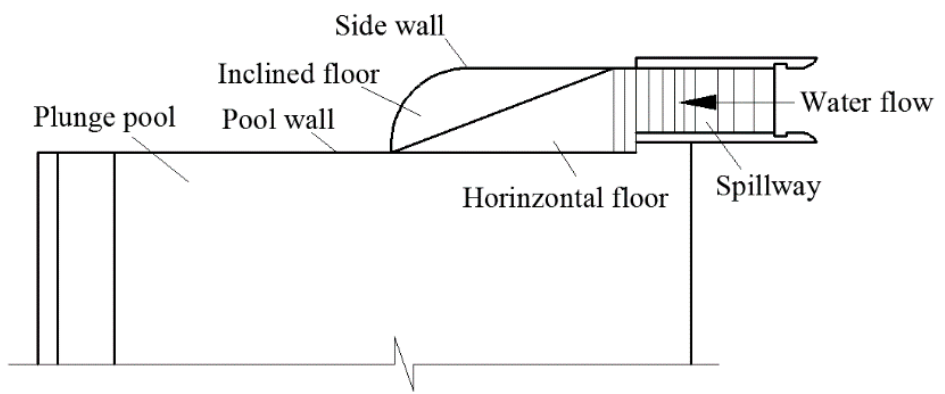

(b)

Figure 1. Definition of the streamwise-lateral discharge spillway: (a) 3-D model; (b) plan view. 
The typical flow pattern of the physical model is shown in Figure 2. When the water flow moves downstream in the spillway, the pressure on the left side is reduced to the atmospheric pressure, while the pressure on the right side remains the hydrodynamic pressure. There is a pressure difference due to the specific design, and the water will flow transversely into the plunge pool and the streamwise-lateral discharge will be generated. When the water flow reaches the end of the spillway, the water is restrained by the inclined floor and the anti-arch side wall, and the free jet is then generated and stretches in the air above the plunge pool. The free jet diffuses pronouncedly in the transverse direction above the plunge pool in the very limited area, showing a "curling type" in the air. This will make a beneficial contribution to the energy dissipation through three aspects: (1) The water thickness is thin and the flow discharge per unit width dropping into the plunge pool is small; (2) the aeration of the free jet is fully developed as it diffuses in the air; and (3) the ratio of the shearing dissipation area in the plunge pool increases.

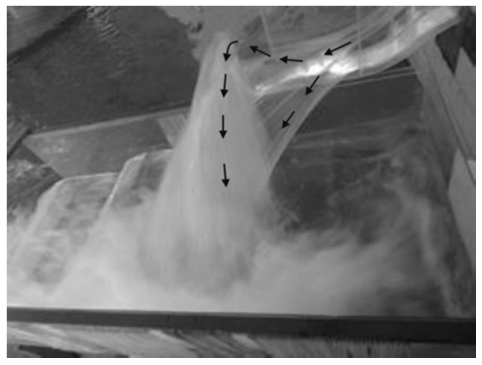

(a)

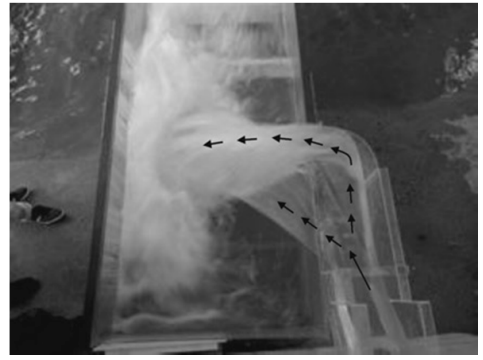

(b)

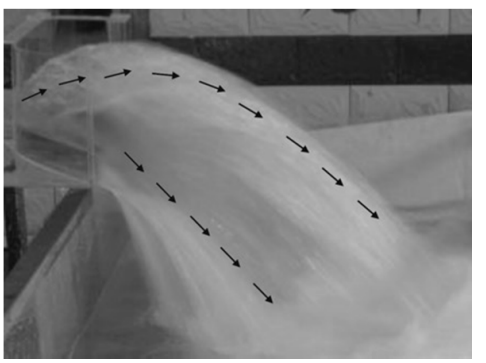

(c)

Figure 2. Typical pattern of the streamwise-lateral discharge spillway: (a) physical model from the downstream view; (b) physical model from the lateral view; (c) ski-jump flow.

To obtain the detained characteristics of configuration and diffusion of the streamwise-lateral ski-jump flow discharge spillway, it is practically impossible to see the jet configuration due to the failure of exiting measurements on the complex 3-D flow. The physical experiments can only provide some jet length and pressure distribution on the floor in order to describe the jet flow pattern. However, the numerical simulation can provide the entire jet field with detailed water profile and velocity distribution in the jet diffusion process. Thus, the physical model test and numerical simulation were used in this paper to systemically study the new design of streamwise-lateral ski-jump flow discharge spillway.

\section{Investigation Methods and Definition of the Free Jet Flow Pattern}

\subsection{Physical Model}

The study of the formation of the streamwise-lateral flow discharge spillway is based on energy dissipation in a certain hydropower station. The size of the plunge pool is 88 (length) $\times 100$ (width) $\mathrm{m}^{2}$, and the vertical distance from the horizontal floor to the bottom wall of the plunge pool is $H_{0}=43 \mathrm{~m}$. The length of the horizontal floor $L=55 \mathrm{~m}$, with $W=21 \mathrm{~m}$ in width. The straight length of the side wall is $L_{\mathrm{b}}=36.4 \mathrm{~m}$, with the anti-arch radius $R=19 \mathrm{~m}$ and the deflection angle $\theta=96^{\circ}$ in the anti-arch structure. The angle $\alpha$ of the inclined floor ranges from $0^{\circ}$ to $60^{\circ}$, as shown in Figure 3 . The flow discharge is $4016 \mathrm{~m}^{3} / \mathrm{s}$, with discharge per unit width $q_{\mathrm{w}}=251 \mathrm{~m}^{3} /(\mathrm{s} \cdot \mathrm{m})$. The tail water depth is $18 \mathrm{~m}$ deep. The scale of a normal model is 1:60 based on the Froude criterion for experimental study. Considering that the roughness coefficient of the concrete in the prototype is 0.0140 and the roughness scale is $60^{1 / 6}=1.979$, the theoretical value of the roughness coefficient is 0.0071 . The physical model is made of transparent plexiglass with a roughness coefficient of 0.0079 . The present physical model is approximately satisfactory for the similarity of boundary roughness between the model and prototype.

Considering the 1:60 scale of the physical model, the approach flow Froude number $\mathrm{Fr}=\mathrm{V} /(\mathrm{gh})^{0.5}$ is about 3.73 with a Reynolds number $R e=V h / v$ of $1.83 \times 10^{5}$, where $v$ is the kinematic water viscosity, 
$g$ is the gravitational acceleration, and $V=3.2 \mathrm{~m} / \mathrm{s}$ and $h=0.075 \mathrm{~m}$ are the mean velocity and depth of the approach flow on the horizontal floor, respectively. Thus, the present study focuses on the typical pattern of ski-jump flow in a streamwise-lateral discharge spillway, jet trajectory and distribution of mean pressure on the bottom floor of a basin, which satisfies the Froude criterion. The scale effect on air-water properties of supercritical flow cannot be neglected with regards to the surface tension and viscosity effects in high-speed flows [20].

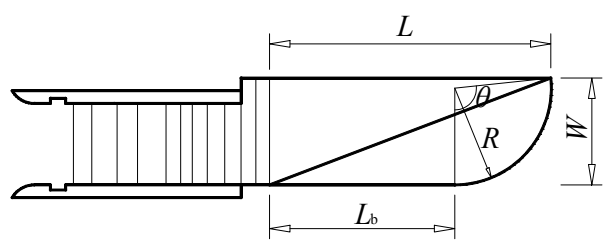

(a)

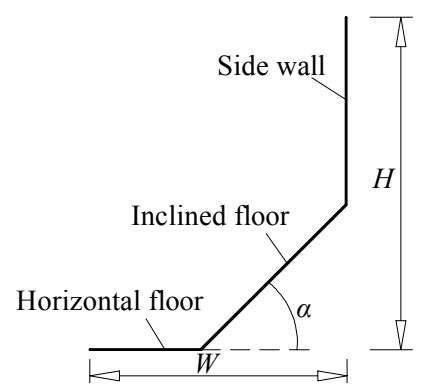

(b)

Figure 3. Sketch with relevant parameters: (a) plan view; (b) sectional view.

A thin plate wire with a graduated cylinder was set downstream for a water flow discharge measurement to the nearest $0.1 \mathrm{~L} / \mathrm{s}$, and the water level was read with a conventional point gauge to an accuracy of $0.1 \mathrm{~mm}$. The jet trajectory of the ski-jump flow was measured at about $5 \mathrm{~min}$, ensuring it did not change much with the time between observations. The pressure signal was measured using a series of pressure sensors (CY201, Test, Inc.: Chengdu, China) and an acquisition device (RS485-20, Test, Inc.: Chengdu, China). The accuracy of the pressure sensor was $0.1 \%$ of the $100 \mathrm{kPa}$ full scale. The pressure time-domain process was sampled at $100 \mathrm{~Hz}$ for $10 \mathrm{~s}$, which was adequate to evaluate the pressure fluctuation under the present hydraulic conditions. The pressure measurement system was calibrated by hydrostatic operation before each test was conducted to ensure measurement reliability. The time mean pressure $P$ was obtained using the time-domain process $p$, and the maximum mean pressure $p_{\mathrm{m}}$ was determined as $p_{\mathrm{m}}=P-P_{0}$.

\subsection{Numerical Simulation}

In the present work, the Fluent computer code (Fluent Inc.: Pittsburgh, PA, USA, 2005) was used to simulate the ski-jump flows of the streamwise-lateral discharge spillway. The Renormalization Group $k-\varepsilon$ turbulent model was employed, which is an effective method to simulate the ski-jump flow movement in detail [21]. The governing equations are as follows:

Continuity equation:

$$
\frac{\partial \rho}{\partial t}+\frac{\partial \rho u_{i}}{\partial x_{i}}=0
$$

Momentum equation:

$$
\frac{\partial \rho u_{i}}{\partial t}+\frac{\partial\left(\rho u_{i} u_{j}\right)}{\partial x_{j}}=-\frac{\partial p}{\partial x_{i}}+\frac{\partial}{\partial x_{j}}\left[\left(\mu+\mu_{t}\right) \times\left(\frac{\partial u_{i}}{\partial x_{j}}+\frac{\partial u_{j}}{\partial x_{i}}\right)\right]
$$

$k$ (turbulent kinetic energy) equation:

$$
\frac{\partial \rho k}{\partial t}+\frac{\partial\left(\rho u_{i} k\right)}{\partial x_{i}}=\frac{\partial}{\partial x_{i}}\left[\left(\mu+\frac{\mu_{t}}{\sigma_{k}}\right) \times \frac{\partial k}{\partial x_{i}}\right]+G_{k}-\rho \varepsilon
$$

$\varepsilon$ (dissipation rate of turbulent kinetic energy) equation:

$$
\frac{\partial \rho \varepsilon}{\partial t}+\frac{\partial\left(\rho u_{i} \varepsilon\right)}{\partial x_{i}}=\frac{\partial}{\partial x_{i}}\left[\left(\mu+\frac{\mu_{t}}{\sigma_{\varepsilon}}\right) \times \frac{\partial \varepsilon}{\partial x_{i}}\right]+C_{1 \varepsilon} \rho \frac{\varepsilon}{k} G_{k}-C_{2 \varepsilon} \rho \frac{\varepsilon^{2}}{k}
$$


where $t$ is time. $\rho$ and $\mu$ are the average density of the volume fraction and molecular viscosity, respectively. $p$ is the pressure and $G_{k}$ represents the generation of turbulence kinetic energy due to the mean velocity gradients. $\mu_{t}$ is the turbulent viscosity which can be deduced for the turbulence intensity $k$ and energy dissipation rate $\varepsilon$ :

$$
\mu_{t}=C_{\mu} \frac{k^{2}}{\varepsilon}, C_{1 \varepsilon}=1.42-\frac{\eta\left(1-\frac{\eta}{\eta_{0}}\right)}{1+\beta \eta^{3}}, \eta=\frac{S k}{\varepsilon}, S=\sqrt{2 \overline{S_{i j}} \overline{S_{i j}}}, \overline{S_{i j}}=\frac{1}{2}\left(\frac{\partial u_{i}}{\partial x_{j}}+\frac{\partial u_{j}}{\partial x_{i}}\right)
$$

where $S$ is the modulus of the mean strain rate tensor. The detailed values are shown in Table 1.

The Volume of Fluid (VOF) method was used to simulate the free surface and air fraction of ski-jump flow. The governing equation for water fraction $\alpha_{\mathrm{w}}$ is:

$$
\begin{gathered}
\frac{\partial \alpha_{\mathrm{w}}}{\partial t}+u_{i} \frac{\partial \alpha_{\mathrm{w}}}{\partial x_{i}}=0 \\
\rho=\alpha_{\mathrm{w}} \rho_{\mathrm{w}}+\left(1-\alpha_{\mathrm{w}}\right) \rho_{\mathrm{a}} \\
\mu=\alpha_{\mathrm{w}} \mu_{\mathrm{w}}+\left(1-\alpha_{\mathrm{w}}\right) \mu_{\mathrm{a}}
\end{gathered}
$$

where $u_{i}$ is the velocity components and $x_{i}$ is the coordinates $(i=1,2,3) . j$ is the sum suffix. The air-water interface is tracked by solving the continuity equations. The sum of the water and air volume fraction was one in the controlling body. The $\rho_{w}$ and $\rho_{a}$ are the density of water and air, respectively. The $\mu_{w}$ and $\mu_{a}$ are the viscosity of water and air, respectively. When $\alpha_{\mathrm{w}}=0$, it means there is full of air; when $\alpha_{\mathrm{w}}=1$, it represents the air fraction of fluid is 0 . When $0<\alpha_{\mathrm{w}}<1$, it means the certain controlling volume. The total fraction in a certain controlling body is $\alpha_{\mathrm{w}}+\alpha_{\mathrm{a}}=1$. Note that, although the VOF model can give an aeration result in the free surface area, the air concentration distribution and aeration development along the jet trajectory is different to the real situations due to the complex air-water interaction and bubble diffusion process. In the present study, the simulated results will be used for the analysis on formation of ski-jump flow released from the streamwise-lateral spillway, which is little affected by the aeration. The detailed hydraulic characteristics, including jet trajectory and impact pressure on the pool floor, will be analyzed based on the physical model results. The control volume method is introduced to discretize the partial differential equations, and the SIMPLER method, which has good convergence characteristics, is employed for numerical simulation [22,23].

In the present research, both structured and unstructured meshes were used. Unstructured mesh was employed in the streamwise-lateral spillway area due to the complex geometry condition. Structural mesh was used for other regions. Mesh size was refined until the computed results were independent of the size of the scale, based on the fact that the calculated water profile and the pressure on the spillway sidewall did not change more than $3 \%$. The uncertainty analysis of different mesh densities showed that the number of meshes was reasonably set to 1,017,033. The approximate $0.5 \times 0.5 \mathrm{~m}^{2}$ mesh size was selected to simulate the pattern of ski-jump flow in the air and its diffusion in the still basin. Based on the authors' previous studies [23-25] on the simulation of high-speed flows (flow velocity exceeded over $30 \mathrm{~m} / \mathrm{s}$ ) in hydraulic engineering, these mesh conditions can make sure the maximum uncertainties for the velocity and pressure characteristics in the whole calculated region were approximately smaller $10 \%$, and the uncertainty in most locations was fairly small. The comparison between the experimental and simulated results with regards to the flow characteristics of the streamwise-lateral discharge spillway are shown in Table 2 for $\alpha=45^{\circ}$, where $Y=0$ is the lateral cross-section at the straight side wall. The distributions of pressure on the side wall and water depth indicate that the simulation results are well in agreement with those of experimental measurements. The vector profile of the flow jet velocity in Figure 4 shows similar flow patterns for the experiments. According to the typical flow pattern of the streamwise-lateral discharge spillway, it is difficult to acknowledge the interior characteristics through experimental 
measurement, due to the irregular "curling" nappe shape and the complicated flow jet movement in the diffusion process. Because the computational water profiles and the pressure on the side wall are well in agreement with the test measurements, the flow patterns are similar between the simulation and the experiment and the complex high-speed fluid can be analyzed with the numerically simulated results. The characteristics of the jet profile and the pressure from the physical model were converted to the prototype according to the length scale. The simulated model was built up based on the real dimensions in the prototype, and the velocity distribution inside the ski-jump flow and stilling basin is the same as the prototype's dimensions.

Table 1. Constants of $k-\varepsilon$ equations.

\begin{tabular}{cccccccc}
\hline Parameters & $\eta_{0}$ & $\beta$ & $C_{\mu}$ & $C_{1 \varepsilon}$ & $C_{2 \varepsilon}$ & $\sigma_{k}$ & $\sigma_{\varepsilon}$ \\
\hline Value & 4.38 & 0.012 & 0.0845 & 1.42 & 1.68 & 0.7179 & 0.7179 \\
\hline
\end{tabular}

Table 2. Comparison of tested and calculated data on the spillway flood discharge $\left(\alpha=45^{\circ}, q_{\mathrm{w}}=251 \mathrm{~m}^{2} / \mathrm{s}\right)$.

\begin{tabular}{|c|c|c|c|c|c|c|c|c|}
\hline \multicolumn{6}{|c|}{ Pressure on the Sidewall of Spillway (m) } & \multirow{2}{*}{\multicolumn{3}{|c|}{ Water Depth along the Side Wall of Spillway (m) }} \\
\hline & $Y=15 \mathrm{~m}$ & & & $Y=18 \mathrm{~m}$ & & & & \\
\hline$H$ & Simulation & Test & $H$ & Simulation & Test & $X$ & Simulation & Test \\
\hline 8.9 & 23.7 & 23.4 & 6.7 & 25.4 & 24.3 & 4.1 & 11.1 & 10.3 \\
\hline 11.3 & 17.0 & 17.6 & 9.2 & 19.6 & 19.1 & 14.1 & 10.5 & 10.3 \\
\hline 12.4 & 13.6 & 12.6 & 11.7 & 13.4 & 13.6 & 23.8 & 11.3 & 11.2 \\
\hline 14.8 & 8.5 & 9.7 & 15.3 & 6.3 & 5.6 & 33.1 & 13.0 & 13.0 \\
\hline 17.1 & 4.8 & 4.5 & 17.8 & 2.4 & 2.7 & 41.5 & 15.4 & 14.6 \\
\hline 19.5 & 1.9 & 1.6 & 21.5 & 1.4 & 0.9 & 49.5 & 19.7 & 19.3 \\
\hline 23.0 & 0.5 & 0.6 & 22.8 & 1.0 & 0.9 & 55.1 & 25.5 & 25.4 \\
\hline
\end{tabular}

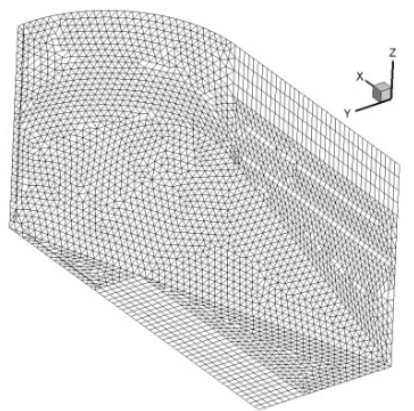

(a)

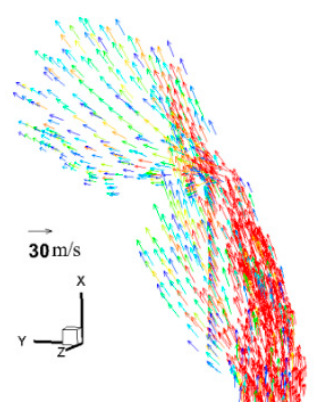

(b)

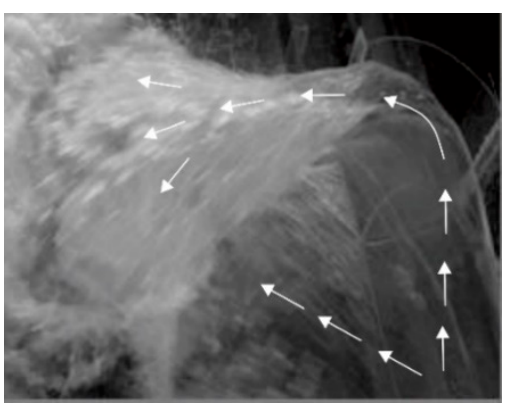

(c)

Figure 4. Comparison of numerical simulation with experimental flow: (a) a sample of computational mesh in the spillway area; (b) velocity vector profile; (c) experimental image.

\section{Results and Discussion}

\subsection{Ski-Jump Flow Pattern}

Figure 5 shows the simulated results about the water profile and velocity vector distributions of the ski-jump flow released from the streamwise-lateral spillway. At the initial area closed to upstream, the pressure near the left side reduces to atmosphere pressure without the left-side wall, while the water near the right side is constrained by the wall. Thus, the water on the left side moves laterally at the cross-section, and releases from the horizontal floor, flowing towards the plunge pool. Meanwhile, water flow on the right side moves along the streamwise direction and "climbs" along the inclined floor to the side wall of the spillway until it reaches the end of the spillway. Due to the coupling constraint of the inclined floor and the anti-arch wall in both streamwise and lateral directions, a thin and widely stretched nappe shape forms in the air, dropping into the plunge pool. In addition, the water moving laterally continues to move in the streamwise direction. Both of the movements contribute to the formation of three-dimensional ski-jump flow. 


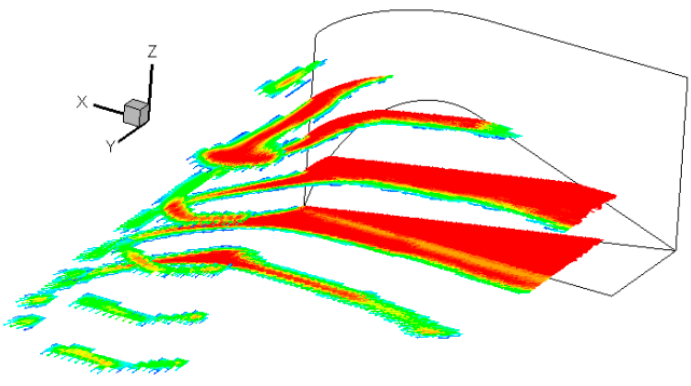

(a)

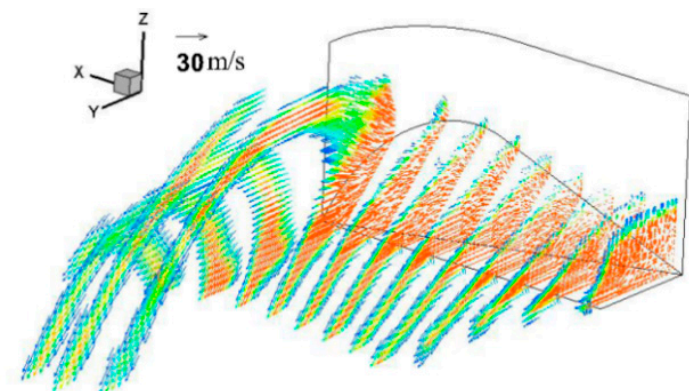

(b)

Figure 5. Jet diffusion of streamwise-lateral ski-jump flow (simulated results for $\alpha=45^{\circ}$ ): (a) water profile at different elevations; (b) velocity vector profile at different cross-sections.

Figure 6 shows the distributions of the detailed flow velocity vector in the air for various elevations. When the water flow leaves the spillway, the jet flow turns to the transverse direction pronouncedly under the effect of coupling constrained by the inclined floor and the anti-arch wall. In addition, the lateral discharge becomes smaller and the streamwise "curling" discharge increases with the decrease of elevation. The " $\cap$ " shape can clearly be seen. The water jet becomes fully stretched in the limited area before dropping into the plunge pool. The thickness of the flow nappe becomes thinner and thinner in the air. This greatly contributes to the aeration and air-water mixture of the flow jet in the diffusion and stretching process, which will accelerate flow velocity attenuation and improve shearing intensity in the plunge pool.

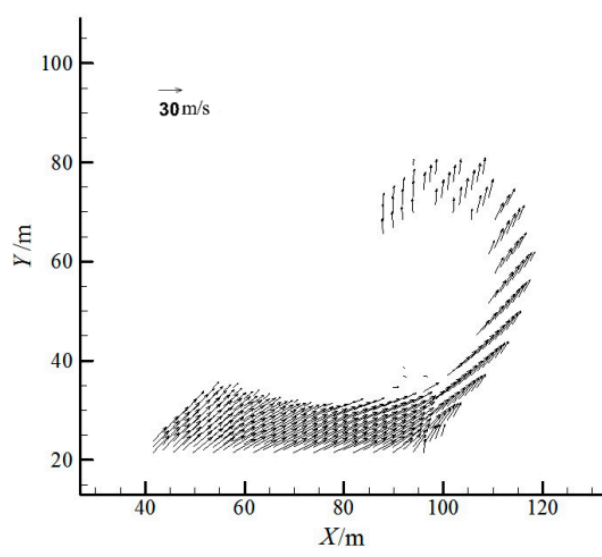

(a)

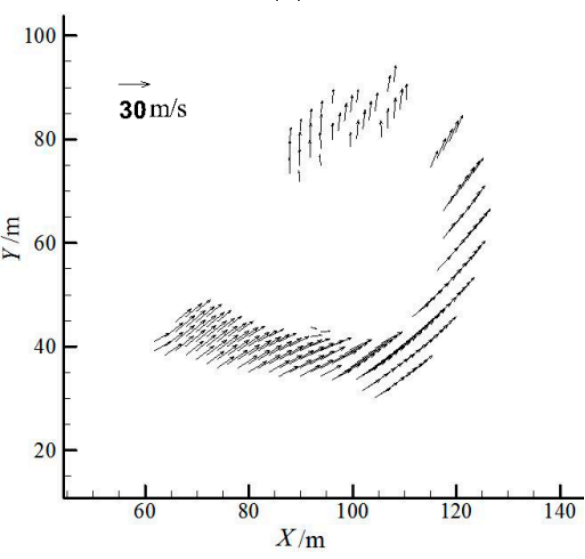

(c)

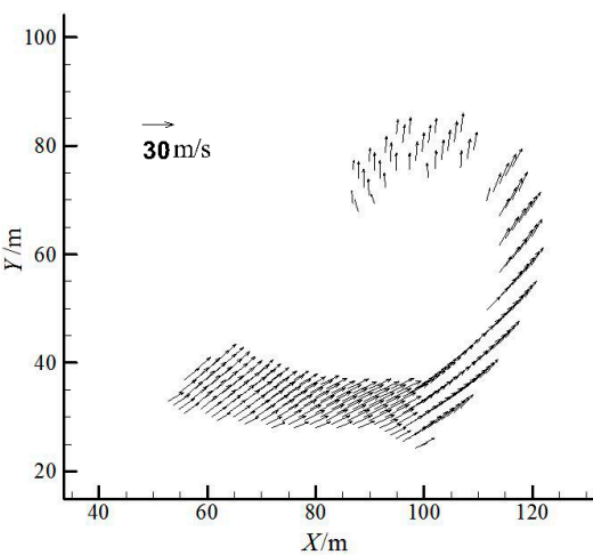

(b)

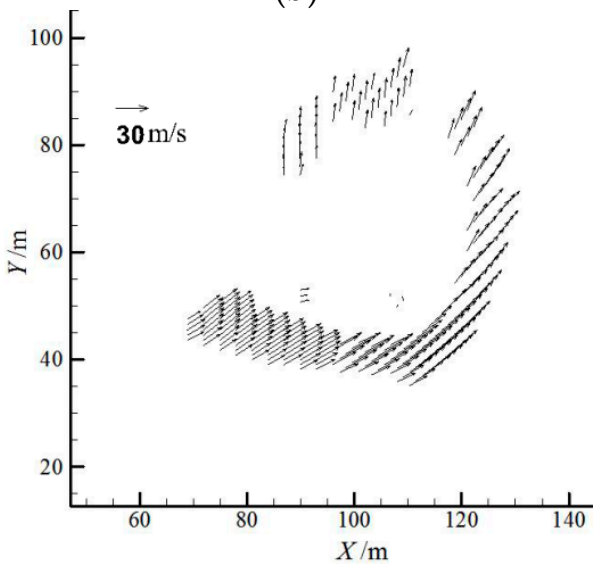

(d)

Figure 6. Velocity vector distributions of free jet flow: (a) $Z=-17 \mathrm{~m}$; (b) $Z=-22 \mathrm{~m}$; (c) $Z=-27 \mathrm{~m}$; (d) $Z=-32 \mathrm{~m}$. 


\subsection{Effect of Inclined Floor on Jet Length}

To describe the free jet trajectory from the experimental results, the nearer jet length $L_{1}$ and the further jet length $L_{2}$ are introduced, as shown in Figure 7 . The further jet length, $L_{2}$, is the longest distance in the lateral direction mainly affected by the coupling effect of the inclined floor and the anti-arch side wall of the spillway; and the nearer jet length, $L_{1}$, is the lateral jet length distance and is affected mainly by the pressure difference in the horizontal floor. The coefficient $\beta=\left(L_{2}-L_{1}\right) / H_{0}$ describes the free jet diffusion in the air, deflecting from the spillway. The increase of $\beta$ indicates that the diffusion performance improves and the stretch of water jet in the air space becomes fully developed. The angle $\alpha$ of the inclined floor influences $L_{1}$ and $L_{2}$ pronouncedly for the otherwise identical conditions. As shown in Figure 8a,b, with the increase of $\alpha$ to $30^{\circ}$, both $L_{1}$ and $L_{2}$ remain unchanged, which indicates that the effect of the inclined floor on the jet length is not distinct. As $\alpha$ further increases to $45^{\circ}, L_{1}$ increases while $L_{2}$ still remains significantly unchanged. The value of $\beta$ decreases slightly which indicates that the water flow pattern is stable, as shown in Figure 8c. For $\alpha>45^{\circ}, L_{1}$ further increases while $L_{2}$ decreases pronouncedly. This results in a significant reduction in $\beta$, which indicates that the diffusion of the jet in the air is not sufficient in the lateral direction. Besides, the further jet length is around five times greater than the nearer jet length for $\alpha<30^{\circ}$, and when $\alpha=60^{\circ}$, the further jet length is around four times greater than the nearer jet length, indicating that the diffusion of the ski-jump flow nappe remained stable. Based on the effect of the inclined angle on the jet length, it is recommended that $\alpha$ is $30 \sim 45^{\circ}$ for a good performance of free ski-jump jet diffusion.

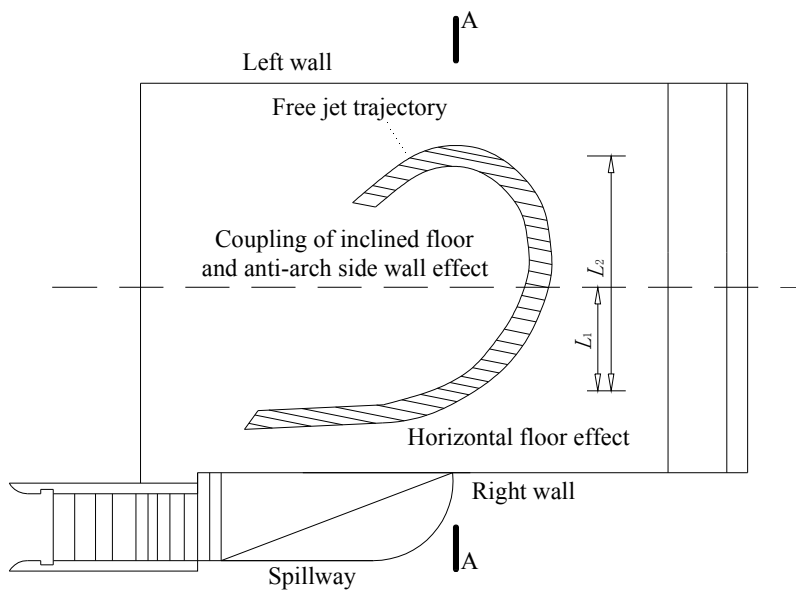

(a)

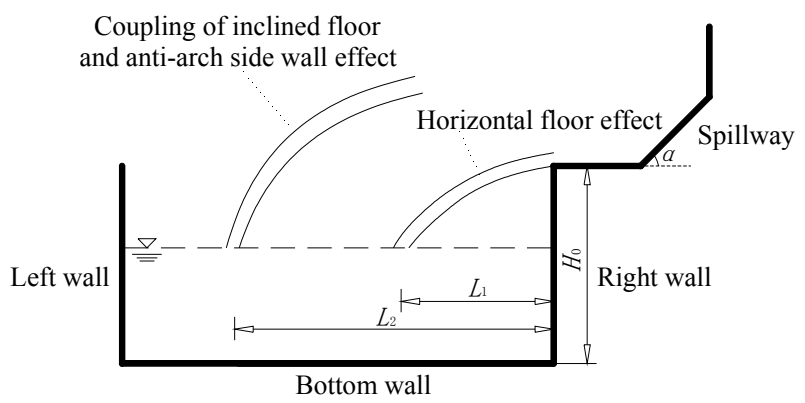

(b)

Figure 7. Sketch of free jet flow deflecting from the streamwise-lateral discharge spillway: (a) plane view; (b) lateral view (A-A). 


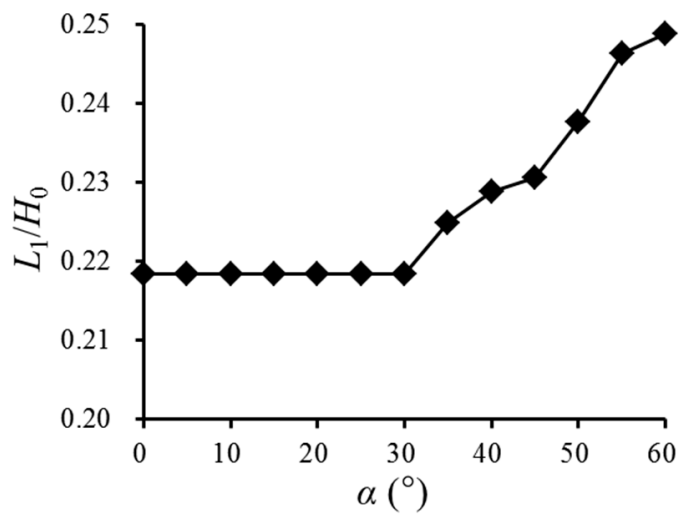

(a)

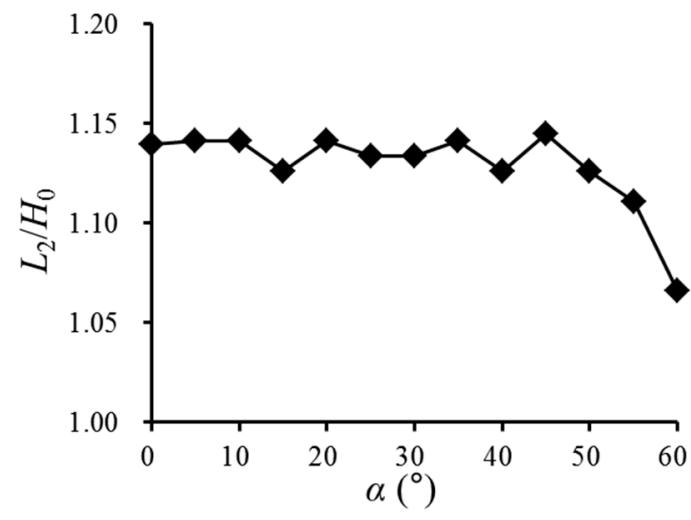

(b)

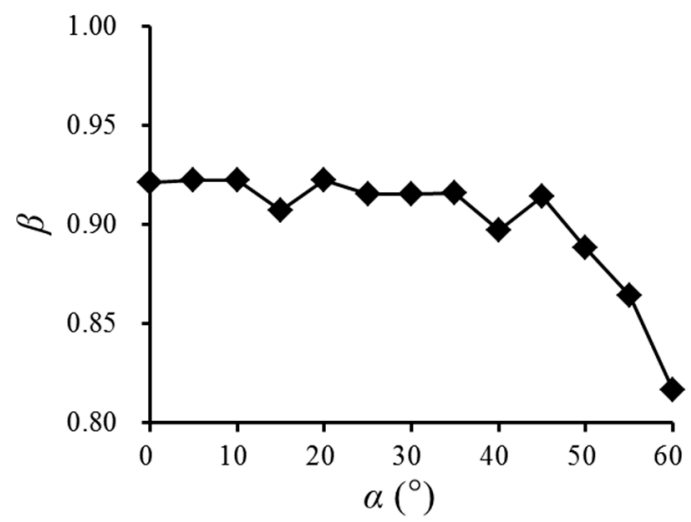

(c)

Figure 8. Effect of inclined angle $\alpha$ on free jet length (a): $L_{1} ;(\mathbf{b}): L_{2} ;(\mathbf{c}): \beta$.

\subsection{Effect of Inclined Floor on Jet Impact Pressure}

The pressure on the bottom floor of the plunge pool is measured experimentally in six areas, Area 1 to Area 6, based on the flow plane-shape, as shown in Figure 9. The maximum impact pressure $p_{\mathrm{m}}$ (defined as the difference between the measured and the mean static pressure in the plunge pool), scaled by the tail water depth $P_{0}$, is strongly affected by the inclined floor angle. When $\alpha=0^{\circ} \sim 30^{\circ}$, the increase of $p_{\mathrm{m}} / P_{0}$ is not obvious. While for $\alpha>30^{\circ}$, the $p_{\mathrm{m}} / P_{0}$ becomes larger with an increase of $\alpha$. This is mainly due to the poor effect of the inclined floor constraint on the water flow streamline for a small $\alpha$ condition. Considering that the flow impinging on the anti-arch side wall results in a large amount of energy dissipation, the flow jet's impact pressure on the bottom floor of the plunge pool is relatively low. For a large $\alpha$, the water flow is well coupling-constrained by both the inclined floor and the anti-arch side wall, and the streamline varies relatively smoothly when it becomes totally free from the streamwise-lateral discharge spillway. Larger $\alpha$ causes a lower energy dissipation in the spillway part. Consequently, the flow energy is mainly transported into the plunge pool, resulting in a high impact pressure on the bottom floor. 


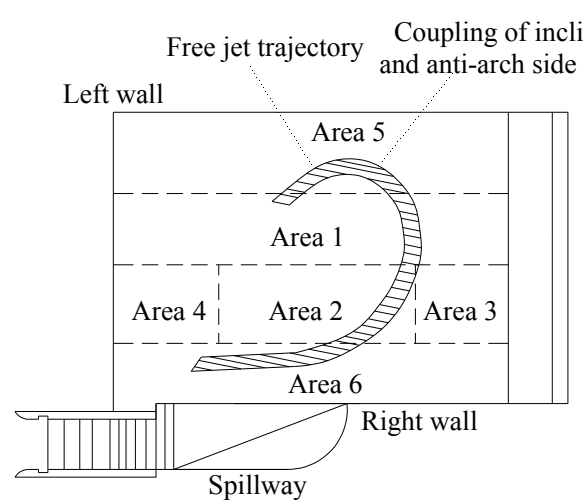

(a)

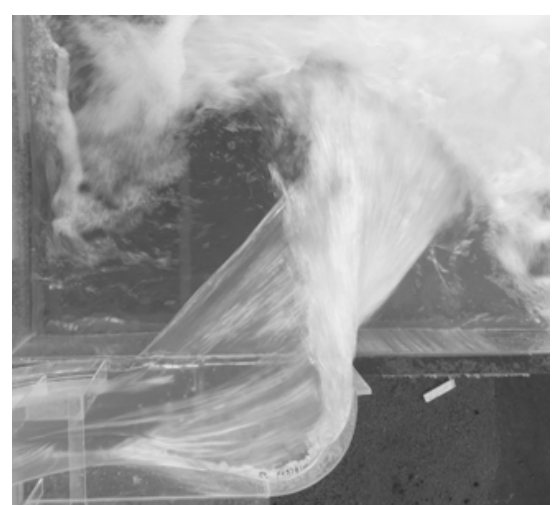

(b)

Figure 9. Flow jet impact in the plunge pool: (a) sketch plane view; (b) experimental image $\left(\alpha=60^{\circ}\right)$.

The specific maximum impact pressure, $p_{\mathrm{m}}$, in each area of the plunge pool describes the pressure and water discharge rate distributions through the stretched flow jet. For different inclined floor angles, the pressure distribution is obviously different, owing to the non-uniform flow jet stretching, as shown in Figure 10. For $\alpha<30^{\circ}$, the pressure profiles distribute smoothly in the whole plunge pool without obvious impact pressure on the bottom floor. The flow jets mainly drop into Area 1, Area 2 and Area 3, which are located in the center of the plunge pool. When $\alpha$ increases to $45^{\circ}$, the flow dropping areas move to Area 1, Area 2 and Area 6, with an obvious increase of impact pressure. This indicates that more water discharge moves in a lateral direction, which is affected by the inclined floor. For $\alpha>45^{\circ}$, the pressure is extremely non-evenly distributed, with greater impact pressure in Area 6. When $\alpha=50^{\circ} \sim 60^{\circ}$, the local impact pressure is near 1.5 2.0 times greater than the mean static pressure in the plunge pool, and this will cause the bottom floor structure to be affected by negative unbalanced force conditions and may cause structural damage with flood discharge.

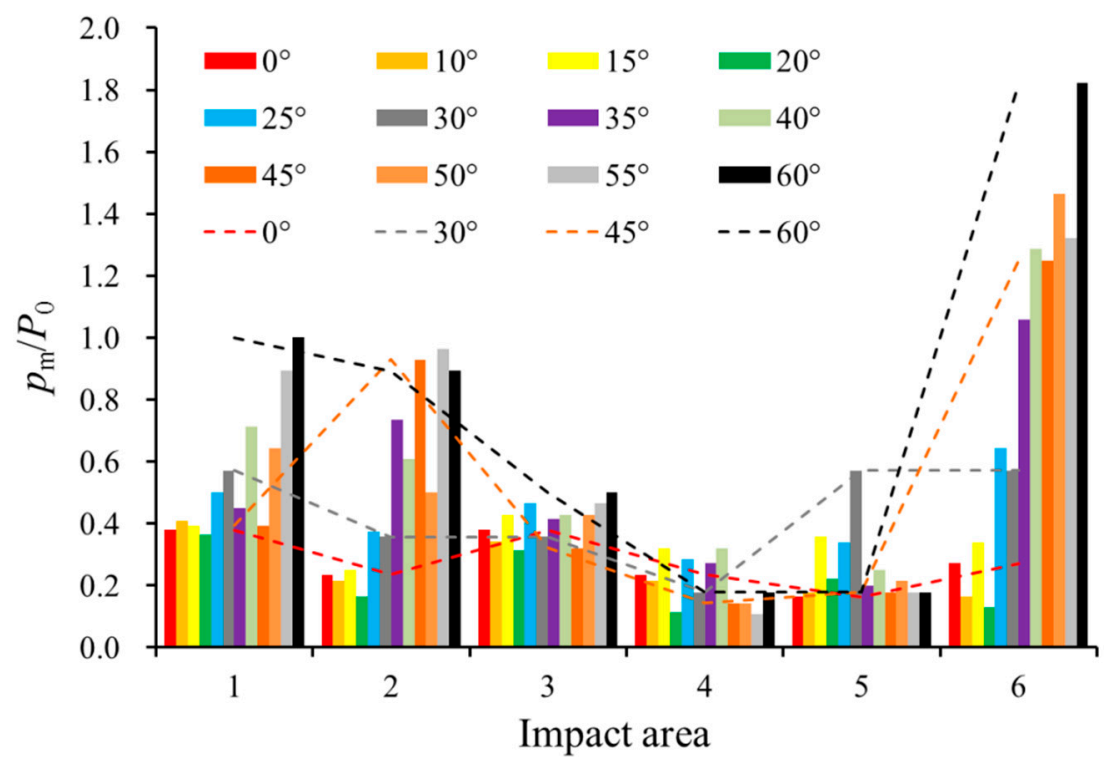

Figure 10. Pressure distributions in the plunge pool affected by the inclined floor angle $\alpha$.

The ski-jump flow released from the streamwise-lateral spillway can be classified basically into three types. The classification is on the basis of the jet length and impact pressure corresponding to the effect of inclined floor and includes the following: (a) Weak effect: $\alpha<30^{\circ}$. The restraint of inclined floor on the ski-jump flow is weak and the jet is mainly affected by the anti-arch radius, which results in the unchanged of jet length (including both nearer and further jet length) and the distribution of impact pressure in the plunge pool. (b) Moderate effect: $30^{\circ}<\alpha<45^{\circ}$. The restraint of the inclined 
floor becomes obvious and the jet diffusion is affected by both the inclined floor and anti-arch radius of side-wall. The nearer jet length increases with the distribution of impact pressure in the plunge pool is moderate. (c) Strong effect: $\alpha>45^{\circ}$. The restraint of inclined floor becomes significant and the stretch of water jet in the air becomes undeveloped. The distribution of impact pressure is extremely asymmetrical with high pressure in the region closed to the spillway.

Figure 11 shows the velocity vector distributions in the plunge pool when the jet flow drops into the pool $\left(\alpha=45^{\circ}\right)$. It is clearly visible that two stable vortexes generate at the nearer and further flow dropping locations in the central part of the plunge pool. With the decrease of elevation, the vortexes' locations move slightly to the left side and the intensive velocity of the vortex attenuates (Figure 11a-c), dispersing near the pool bottom (Figure 11d). Moreover, the velocity attenuates quickly in both the $X$ and $Y$ directions. In terms of structural safety, there is no standing vortex penetrating the bottom floor of the plunge pool for the large flood discharge operation, although the flow pattern dropping into the pool is irregular with the velocity magnitude and direction gradient non-uniformly distributed. The average velocity of the tail-ridge area is about $3.41 \mathrm{~m} / \mathrm{s}$, indicating that the streamwise-lateral ski-jump flow is beneficial for energy dissipation due to the turbulent shearing and aeration without the risk of damage to the plunge pool structure.

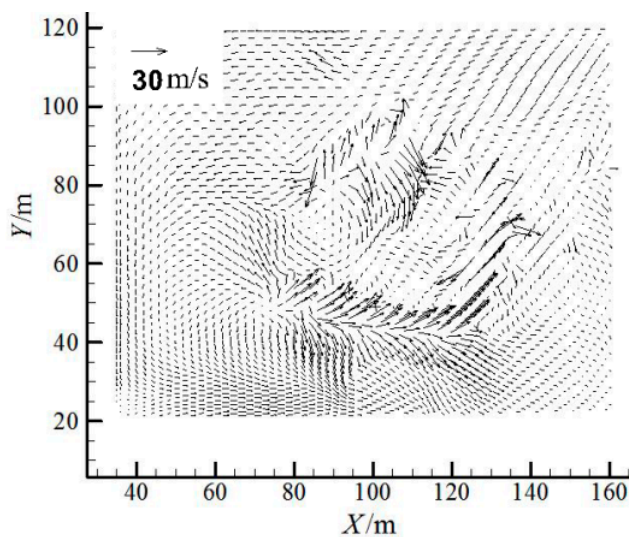

(a)

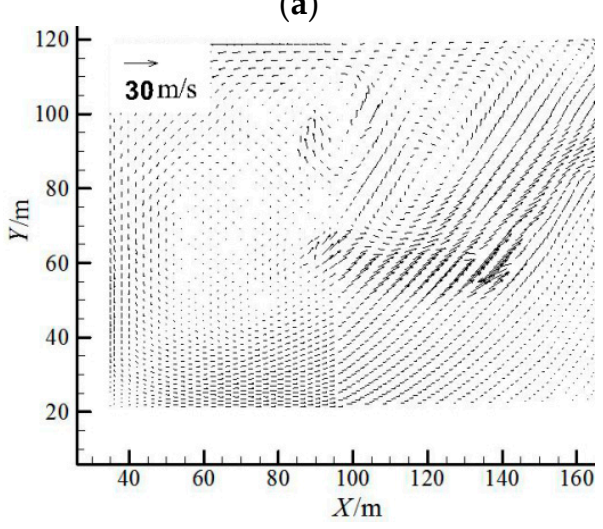

(c)

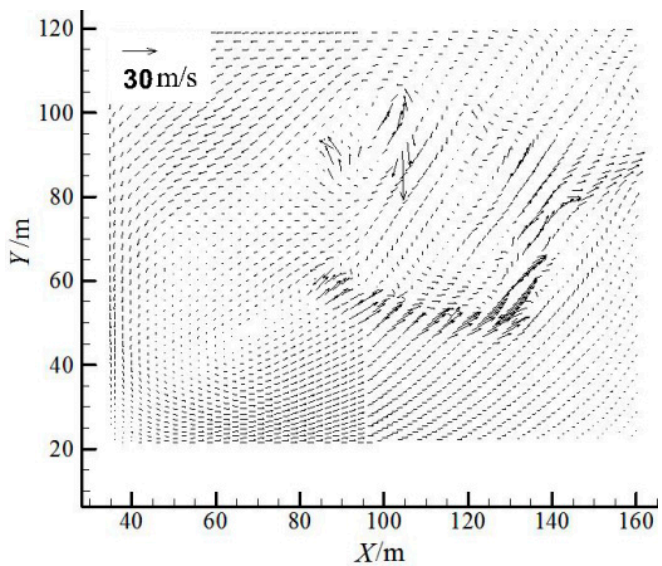

(b)

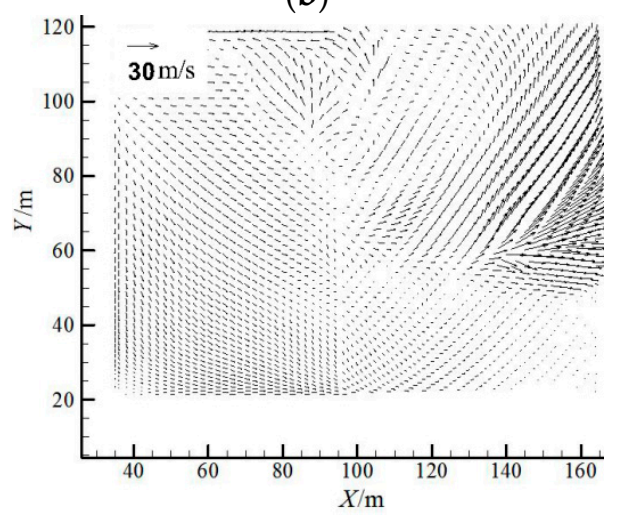

(d)

Figure 11. Velocity vector distributions in the plunge pool: (a) $Z=-38 \mathrm{~m}$; (b) $Z=-44 \mathrm{~m}$; (c) $Z=-50 \mathrm{~m}$; (d) $Z=-58 \mathrm{~m}$.

Figure 12 shows the velocity vector distributions at the cross-section $(X=100 \mathrm{~m}$, the furthest lateral jet length for $\alpha=45^{\circ}$ ). The incident angles of nearer and further jet flow are almost the same, which are moderate to take full advantage of the water depth to dissipate the jet flow kinetic energy. The uniform distributions of velocity near the left side and the bottom wall of the plunge pool confirms that no obvious impact is caused by the ski-jump flow. The slight air-water surge is only at the dropping area and hardly influences the symmetric water flow pattern in the total plunge pool without 
a difference of water depth between the left and right side. This is because the thickness of the water jet dropping into the pool is thin and the aeration becomes fully developed as it diffuses into the air. Both of them will make efficient contributions to improving the energy dissipation and jet impact effect.

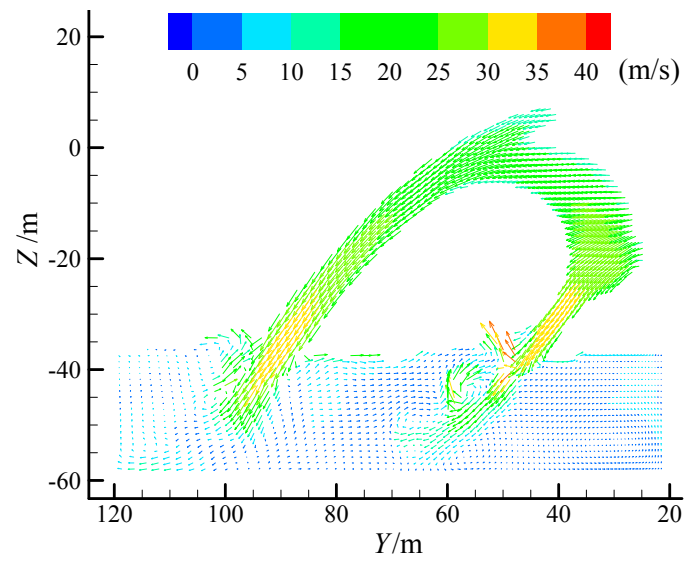

Figure 12. Lateral velocity vector profile of streamwise-lateral ski-jump flow $(X=100 \mathrm{~m})$.

Based on the experimental tests and numerical simulation results, the flow characteristics of the streamwise-lateral spillway can be described as follows: (1) When the water flows on the spillway, some of the water discharge moves in a lateral direction without one side wall constraint, dropping into the plunge pool; (2) when the other water reaches the end of the spillway, a stretched ski-jump flow jet generates in the limited lateral space above the plunge pool, due to the coupling effect of the inclined floor and the anti-arch side wall; (3) when the water flow impinges into the plunge pool, submerged jet forms cause energy to dissipate through the drastic flow shearing and turbulent disturbance. The present study shows that for $\alpha=30^{\circ} \sim 45^{\circ}$, the structural design of the streamwise-lateral discharge spillway performs well in controlling the ski-jump flow in terms of the high-speed and large flood discharge conditions, resulting in well jet diffusion in the air and the water discharge rate having uniform distribution.

\section{Conclusions}

A new type of design for streamwise-lateral ski-jump flow discharge in the spillway is introduced in this paper. In contrast to the traditional spillway, in this design, the side wall next to the plunge pool is removed, and an inclined floor is set between the horizontal bottom floor and the right-side wall with an anti-arch deflection design at the end. Lateral discharge generates along the streamwise flow discharge due to the natural pressure difference between the two sides. The free jet flow fully diffuses into the limited area, and is affected by the coupling constraint of the inclined floor and the anti-arch side wall.

The optimum free jet flow diffusion results occurred in the range of inclination angles of $30^{\circ} \sim 45^{\circ}$. The experimental and simulated results show the interior characteristics of the streamwise-lateral jet flow. This fully stretched free jet flow will make a beneficial contribution to the reduction in discharge per unit width dropping into the plunge pool, and an improvement in energy dissipation performance without an obvious impact on the plunge pool. Therefore, the application of the streamwise-lateral flow discharge spillway has a promising future in hydraulic engineering.

Author Contributions: This paper is a product of joint efforts of the authors who worked together on the experimental model tests. J.D. has a scientific background in applied hydraulics while W.W. and F.Z. conducted the experimental and numerical simulation investigations. J.D. and Z.T. generated the proposed effects of outlet structure on the hydraulic characteristics while J.D. and W.W. tested the methods and wrote this paper.

Funding: Resources to cover the Article Processing Charge were provided by the National Natural Science Foundation of China (Grant No. 51609162).

Conflicts of Interest: The authors declare no conflict of interest. 


\section{References}

1. Xu, W.L.; Luo, S.J.; Zheng, Q.W.; Luo, J. Experimental study on pressure and aeration characteristics in stepped chute flows. Sci. China Technol. Sci. 2015, 58, 720-726. [CrossRef]

2. Chanson, H. Energy Dissipation in Hydraulic Structures; IAHR Monograph; CRC Press: Boca Raton, FL, USA, 2015.

3. Liu, P.Q. Energy Dissipater Theory of Modern Dam Construction; Science Press: Beijing, China, 2010. (In Chinese)

4. Heller, V.; Hager, W.H.; Minor, H.E. Ski jump hydraulics. J. Hydraul. Eng. 2005, 131, 347-355. [CrossRef]

5. Hager, W.H.; Boes, R.M. Hydraulic structures: A positive outlook into the future. J. Hydraul. Res. 2014, 52, 299-310. [CrossRef]

6. Chanson, H. Aeration of a free jet above a spillway. J. Hydraul. Res. 1991, 29, 655-667. [CrossRef]

7. Lenau, C.W.; Cassidy, J.J. Flow through spillway flip bucket. J. Hydraul. Div. 1969, 95, 633-648.

8. Mason, P.J.; Arumugam, K. Free jet scour below dams and flip buckets. J. Hydraul. Eng. 1985, 111, $220-235$. [CrossRef]

9. Juon, R.; Hager, W.H. Flip bucket without and with deflectors. J. Hydraul. Eng. 2000, 126, 837-845. [CrossRef]

10. Erpicum, S.; Archambeau, P.; Dewals, B.; Pirotton, M. Experimental investigation of the effect of flip bucket splitters on plunge pool geometry. Wasserwirtschaft 2010, 4, 73-80.

11. Mason, P.J. Practical guidelines for the design of flip buckets and plunge pools. Water Power Dam Constr. 1993, 45, 40-45.

12. Li, S.; Liang, Z. Gravity-affected potential flows past spillway flip buckets. J. Hydraul. Eng. 1988, 114, 409-427.

13. Rajan, B.H.; Shivashankara, R.K.N. Design of trajectory buckets. J. Irrig. Power 1980, 37, 63-76.

14. Steiner, R.; Heller, V.; Hager, W.H.; Minor, H.E. Deflector Ski Jump Hydraulics. J. Hydraul. Eng. 2008, 134, 562-571. [CrossRef]

15. Alias, N.A.; Mohamed, T.A.; Ghazali, A.H.; Noor, M.J.M.M. Impact of takeoff angle of bucket type energy dissipater on scour hole. Am. J. Appl. Sci. 2008, 5, 117-121. [CrossRef]

16. Wu, J.H.; Ma, F.; Yao, L. Hydraulic characteristics of slit-type energy dissipaters. J. Hydrodyn. 2012, 24, 883-887. [CrossRef]

17. Pfister, M.; Hager, W.H. Deflector-generated jets. J. Hydraul. Res. 2010, 47, 466-475. [CrossRef]

18. Li, N.W.; Liu, C.; Deng, J.; Zhang, X.Z. Theoretical and experimental studies of the flaring gate pier on the surface spillway in a high-arch dam. J. Hydrodyn. 2012, 24, 496-505. [CrossRef]

19. Zhang, T.; Chen, H.; Xu, W.L. Allotypic hybrid type flip bucket. II: Effect of contraction ratio on hydraulic characteristics and local scour. J. Hydroelec. Eng. 2013, 32, 140-146. (In Chinese)

20. Felder, S.; Chanson, H. Scale effects in microscopic air-water flow properties in high-velocity free-surface flows. Exp. Therm. Fluid Sci. 2017, 83, 19-36. [CrossRef]

21. Xu, W.L.; Liao, H.S.; Yang, Y.Q.; Wu, C.G. Computational and Experimental Investigation on the 3-D Flow Feature and Energy Dissipation Characteristics of Plunge Pools. Chin. J. Theor. Appl. Mech. 1998, 30, $35-42$.

22. Deng, J.; Xu, W.L.; Zhang, J.M.; Qu, J.X.; Yang, Y.Q. A new type of plunge pool-Multi-horizontal submerged jets. Sci. China Technol. Sci. 2008, 51, 2128-2141. [CrossRef]

23. Deng, J.; Yang, Z.L.; Tian, Z.; Zhang, F.X.; Wei, W.R.; You, X.; Xu, W.L. A new type of leak-floor flip bucket. Sci. China Technol. Sci. 2016, 59, 565-572. [CrossRef]

24. Wei, W.R.; Deng, J.; Liu, B. Influence of aeration and initial water thickness on axial velocity attenuation of jet flows. J. Zhejiang Univ. Sci. A 2013, 14, 362-370. [CrossRef]

25. Yu, T.; Deng, J.; Xia, Y.; He, C.L.; Xu, W.L. Numerical simulation of turbulent trajectory flow with turnover nappe. Water Resour. Hydropower Eng. 2005, 36, 37-39. (In Chinese)

(C) 2018 by the authors. Licensee MDPI, Basel, Switzerland. This article is an open access article distributed under the terms and conditions of the Creative Commons Attribution (CC BY) license (http:/ / creativecommons.org/licenses/by/4.0/). 